DOI: $10.17805 /$ ggz.2019.2.4

\title{
Потенциал этнокультурного неотрадиционализма в социальном регулировании межэтнических отношений
}

\author{
С. А. Мадюкова \\ Институт философии и права СО РАН, \\ 2. Новосибирск
}

В статье, подготовленной на основе сообщения на Общероссийской конференции "III Академические чтения памяти Вл. А. Лукова» (4 апреля 2019 г.), этнокультурный неотрадиционализм представлен как теоретическая конщепция и как практика, конкретный образ жизни, обладающий значительным потенциалом для социального регулирования межэтнических отношений. Автор анализирует механизмы учета и использования возможностей этнокультурного неотрадиионализма в таком регулировании.

Ключевые слова: этнокультурный неотрадиционализм; межэтнические отношения; сочиальное регулирование; проблемь культуры

\section{Potential of Ethnocultural Neotraditionalism in Social Regulation of Interethnic Relations}

\author{
S. A. Madyukova \\ Institute of Philosophy and Law, Siberian Branch, \\ Russian Academy of Sciences, Novosibirsk
}

The article comprises the report presented at the All-Russian conference "The Third Academic Readings in the Memory of Vladimir A. Lukov" (April 4, 2019). It represents ethnocultural neotraditionalism as a theoretical conception and as a practice, a specific lifestyle that has a significant potential for social regulation of interethnic relations. The author analyzes the mechanisms of accounting and harnessing capabilities provided by ethnocultural neotraditionalism in such regulation.

Keywords: ethnocultural neotraditionalism; interethnic relations; social regulation; problems of culture

\section{ВВЕДЕНИЕ}

Значимой характеристикой современного общества является развитая система регулирования отношений между людьми. В межэтническом сообществе существенную роль приобретает социальное регулирование межэтнических отношений и взаимодействий. В данной статье мы используем концепт «межэтническое сообщество», введенный В. В. Мархининым и. В. Удаловой (Мархинин, Удалова, 2014) для характеристики неделимой полиэтничной 
группы, объединенной общей территорией проживания и устойчивыми межэтническими взаимодействиями. Понятие «межэтническое сообщество» развивают в своей статье Ю. В. Попков и Е. А. Тюгашев, приходя к выводу, что «чаще причины культурного обособления отдельных этнических групп видятся в традиционалистском менталитете. Он может быть присущ как выходцам из сельской местности того же региона, так и мигрантам из других стран» (Попков, Тюгашев, 2017: 17). В последние десятилетия в крупных российских городах изменяются пропорции этнического состава населения, в значительной степени за счет миграционных процессов. Интенсивный прирост населения осуществляется как из государств СНГ, так и за счет внутрироссийской межрегиональной миграции. В работах Ю. В. Попкова понятие «межэтническое сообщество» используется для отображения взаимосвязи этнокультурного многообразия и национального единства страны (Попков, 2013: Электронный ресурс). Мы рассматриваем межэтническое сообщество не только в качестве объекта регулирования межэтнических отношений на разных уровнях (государственном, региональном, муниципальном), но и в качестве самоорганизующегося на локальном (например, на региональном) уровне субъекта (подробнее см.: Ерохина, Мадюкова, Персидская, 2015).

\section{ЭТНОКУЛЬТУРА В ГОРИЗОНТЕ ТЕЗАУРУСНОГО ПОДХОДА}

Важно понимать, что этнокультура в широком смысле представляет собой массивный комплекс компетенций и конкретных навыков и практик, присущих тому или иному этносоциальному сообществу. Она содержит в себя как духовные (в т. ч. конфессиональные), так и материальные компоненты, а также когнитивно-эмоциональное наполнение, включающее ценностные ориентации, практики комфортного сосуществования и др. Применение тезаурусного подхода к исследованию этнокультурных традиций представляется методологически значимым, поскольку в широком смысле тезаурус это сокровищница, нечто, имеющее особую ценность. Под тезаурусом может пониматься определенное накопление: «тезаурус - это структурированное представление и общий образ той части мировой культуры, которую может освоить субъект» (Луков В., Луков Вл., 2006: 559). Принципиальное значение в данном контексте обретает дихотомия «свое - чужое», поскольку в межэтническом сообществе процесс идентификации себя с социальной группой (например, этносом) реализуется именно через отделение принадлежащего данной этнокультуре от других этнокультур. Как отмечают Н. В. Захаров и Вал. А. Луков, «оппозиция “свое — чужое” образует стержень тезауруса и придает ему социальную значимость. На этом строятся “картины мира”... которые формируются постепенно по мере социализации и обретения социальной идентичности субъектом познания» (Захаров, Луков, 2017: 155). Вместе с тем в рамках этнокультурного неотрадиционализма эта оппозиция обретает качественную специфику.

Внутриэтническая передача системы ценностей и конкретного этнокультурного опыта осуществляется посредством трансляции традиций от по- 
коления к поколению. Традиция выступает как в качестве содержания историко-культурного наследия, так и включает в себя сам механизм, совокупность способов трансляции социокультурного опыта. В современных условиях под влиянием глобализационных и миграционных процессов, а также ускорения информационного обмена за счет глобальной сети и СМИ, с одной стороны, отмечается тенденция формирования общемировой «унифицированной» культуры, с другой стороны, в социогуманитарном дискурсе фиксируется всплеск интереса к этничности в широком смысле, к этническим культурам, а также акцентированное дробление на субэтнические культуры в пределах одного этноса. Одной из характеристик современных форм межэтнических взаимодействий является, таким образом, рост стремления представителей этнокультурных сообществ к возрождению этнокультурных традиций и поддержке собственной этнокультурной отличительности.

В данном контексте важно понимать, что этническая идентичность актуализирована в современности как один из ключевых видов идентичности личности. Она представляет собой разновидность социальной идентичности и выражает осознанную принадлежность к определенной этнической общности как «результат когнитивно-эмоционального процесса осознания себя представителем определенного этноса на основе отождествления с ним и дифференциации от других этносов» (Шергалиева, 2014: 103), как продукт переживания личностью «тождества с одной этнической общностью и отделения от других» (там же). Устойчивость этнической идентичности во многом связана с тем, что она взаимосвязана как с потребностью в нормативном регулировании, так и с базовыми витальными потребностями в виде потребности в безопасности, самосохранении (Долженкова, Попков, 2016). При этом в определенных условиях она может принимать форму национализма и являться причиной межэтнических и межнациональных конфликтов (Мадюкова, Попков, 2010).

Конкретная этнокультура формируется под влиянием географических, климатических и других условий, сообразно историческому развитию этноса. Особенностью современных межэтнических сообществ является трансформация целей обращения к этнокультуре, где социальный запрос на этнокультуру формируется не под влиянием естественных потребностей, продиктованных образом жизни этноса, а обращение к традиции осуществляется непосредственно с целью актуализации своей этнической специфичности, фиксации этнической идентичности и выстраивания определенных поведенческих моделей на ее основе. Воспроизводство этнокультурных традиций в современных условиях берет на себя качественно иную социальную функцию: оно дает не только возможность сохранения и трансляции локального этнокультурного опыта, но и может выступать в качестве определенного «якоря» в процессе адаптации к быстро меняющимся условиям. Традиция становится предметом ряда интеллектуальных операций с целью обоснования выбираемого будущего поведения через референцию к авторитету прошлого (Александров, 1991: 10). Традиционные культуры, с точки зрения Н. Н. Зарубиной, «становятся легитимирующей основой преобразований, 
осуществляемых не на основе отрицания традиционного, а его органического включения в процессы осовременивания» (Зарубина, 1998: 196).

Традиция обретает возрастающее значение в процессе фиксации этнокультурного отличия одного локального сообщества от других. И фундаментом такого отличия является, в первую очередь, его история, прошлое. В процессе обращения к прошлому в рамках неотрадиционализма может быть произведена своеобразная селекция, выборочное «вспоминание» того, что созвучно потребностям настоящего. При этом прошлое неосознанно (либо как раз сознательно) может быть искажено, идеализировано.

Отметим, что одной из наиболее важных характеристик традиционного общества является определенная система регламентации повседневного поведения людей: все важные этапы жизни человека освящаются соответствующими ритуалами. Традиция органично встроена в повседневную жизнь, и усвоение ее новым поколением происходит естественным образом. Принципиально важно, что в традиционном обществе трансляция традиционных знаний и конкретных навыков осуществляется устно-зрительным путем, в процессе включенного наблюдения и/или личного участия в конкретном ритуале, а сохранение знаний осуществляется в устной традиции с помощью человеческой памяти. Закрепление полученной с помощью такого опыта информации обеспечивается в процессе усвоения семейных и общественных традиций благодаря непосредственному участию в повседневных практиках, устоявшихся обрядах.

Современная же традиция обладает комплексом специфических характеристик. Она обладает таким свойством, как адаптивность, гибкость, способность видоизменяться, приобретая обновленную форму, а иногда и содержание. Меняются инициаторы воспроизводства традиционного знания, его непосредственные носители, цели актуализации этнокультурных традиций. Трансформируются также способы и каналы трансляции традиций: в современном мире, в отличие от традиционного, начинают доминировать публичные каналы (средства массовой информации, система образования, учреждения культуры).

Следовательно, этнокультурный неотрадиционализм - это процесс одновременного воспроизводства традиции и ее трансформации, адаптации к современным условиям. В результате осуществляется развитие традиции посредством включения новации. В рамках неотрадиционализма этнокультурные традиции выполняют новые социальные функции, посредством которых осуществляется этническая идентификация индивида и локального сообщества. Такие «новые традиции» характеризуются подчас упрощением соответствующих практик, «забыванием» трудновоспроизводимых элементов конкретного обряда, а также рефлексивностью и символическим содержанием. Стремление к воспроизводству этнической культуры становится значимым ресурсом самоутверждения этнических сообществ.

Этнокультурный неотрадиционализм, существуя в межэтническом сообществе, помогает решить задачу обозначения границ «своей» общности и служит ориентиром в пространстве межэтнических взаимодействий. Вклю- 
ченность в традицию способствует формированию ряда социальных чувств, например, локального патриотизма. Этнокультурный неотрадиционализм проявляется в комплексе «этнических маркеров»: ценности родного языка, национальной кухни, популярности «своих» имен либо имен на двух языках, этнической атрибутики в одежде и прическе, традиционных верований и т. д. (Мадюкова, 2008).

Особым маркером этнокультурного неотрадиционализма является актуализация религиозности, повышение взаимосвязи между этнической и конфессиональной идентичностью, вплоть до их отождествления. Стоит согласиться с утверждением М.Н. Ефименко, что «этнические и религиозные факторы взаимодействуют друг с другом следующим образом: этнос формирует религию и ее традиции; религиозная система с помощью ряда средств, в том числе и традиции, конструирует этнос; этнический фактор придает неповторимый колорит и своеобразие конфессиональному миру, активно влияет на формирование религиозного сознания и религиозной психологии» (Ефименко, 2001: 14). Следовательно, можно зафиксировать рост популярности традиционных верований и тесную связь в формировании конфессиональной и этнической идентификации.

В своей крайней форме этнокультурный неотрадиционализм может принимать негативные формы, способствовать конфликтному развитию межэтнических отношений внутри полиэтничного сообщества. С. С. Апажева по этому поводу пишет: «Общая тенденция развития традиции и традиционности в российском социуме указывает на процесс оформления в современных условиях российского этнокультурного консерватизма. Негативной стороной этого явления выступает этноэтатизм ${ }^{1}$, подводящий к разрушению федеративного устройства государства и осуществляющий, по сути, подмену интересов культурного развития народов интересами властных элит. Предпочтительным развитием такого консерватизма следует считать один из его умеренных вариантов, ориентированных не на господство одного народа над другим (главенства одной культуры над другой), а на отстаивание уникальности национальных форм развития, в противовес всевозможным проектам, основанным на их отрицании. Уникальность этнокультурных форм должна поддерживаться в пределах единого правового и экономического пространства российского социума» (Апажева, 2003: 10; курсив источника. - C. A.).

Учитывая политический аспект развития неотрадиционализма, а также возможные спекуляции традиционным, А. И. Пика фиксирует, что «еще в 1920-е годы, в центральных государственных органах, среди ученых и практических работников определились два течения — “традиционалистов” и “модернизаторов”» (Пика, 1996: 48). Первые, с его точки зрения, считали, что роль государства ограничивается содействием адаптации малочисленных этносов к динамичному индустриальному обществу, ограждением их среды обитания и культуры от внешних воздействий, тогда как собственно общественно-историческое развитие таких этносов есть их собственное дело. Мо-

\footnotetext{
${ }^{1}$ Исправлено. В источнике: «этно-этатизм».
} 
дернизаторы же отстаивали точку зрения, что «дело социальноисторического развития малочисленных этносов слишком ответственно, чтобы доверить его им самим. Они полагали, что государство ради достижения общественных идеалов вправе регулировать, изменять социокультурные институты и структуры малочисленных народов и весь их образ жизни» (там же: 49).

Таким образом, мы приходим к выводу, что этнокультурный неотрадиционализм обладает потенциалом для регулирования межэтнических взаимодействий посредством обращения к собственному культурному багажу и системе ценностей. Являясь формой органичной интеграции этнокультурных традиций и инокультурных новаций, неотрадиционализм способен снимать возможный конфликт этнокультурных ценностей. С другой стороны, неотрадиционализм (по сравнению с традиционализмом) более гибок и восприимчив к привносимым извне (из других традиций и культур) новациям.

Говоря о потенциале этнокультурного неотрадиционализма в процессе социального регулирования межэтнических отношений, отметим, что традиционно выделяют три вида межэтнических взаимодействий: воздействие, содействие и противодействие. Под воздействием традиционно понимается активное влияние одной этнической группы на другую, при этом один этнос обладает характеристиками доминирующего субъекта, а второй — воспринимающего объекта воздействия. Под противодействием понимается противоречие в позициях, влекущее за собой препятствие действиям, противостояние одного этноса другому. Принято считать, что вероятность противодействия возрастает в тех случаях, когда представители этнической группы встречаются с чем-то новым, нетрадиционным для нее - с непривычным складом мышления, нравами и порядками. С нашей точки зрения, неотрадиционализм, органично инкорпорирующий в себя новации, способен снижать градус напряжения в межэтнических взаимодействиях и нивелировать отторжение другой культуры. Проявляясь в том числе как мода на этнический колорит, в этнокультурном неотрадиционализме формируется социальный запрос на «этнокультурное другое» как непонятное, но интересное, непривычное, но красивое. Не случаен в данном контексте рост популярности использования формы юрты на базах отдыха в регионах России с существенной долей тюркского населения (например, Алдын-Булак в Республике Тыва; см.: Этнокультурный комплекс ..., б/д: Электронный ресурс), мода на ношение одежды с использованием этнических орнаментов и атрибутики и даже формирование самостоятельной отрасли в фэшн-индустрии (Ерохина, Мадюкова, 2017). Примеры качественно нового использования традиционного можно наблюдать также в поп-музыке, ювелирном искусстве, «национальных» блюдах в кафе и ресторанах и т. д.

\section{ЗАКЛЮЧЕНИЕ}

Таким образом, этнокультурный неотрадиционализм обладает потенциалом для становления на его основе третьей формы межэтнических взаимодействий - содействия. В рамках содействия взаимодействующие этносы 
обладают едиными целями, равными правами и возможностями для их реализации, оказывая друг другу поддержку и помощь в их достижении.

Следует понимать, что каждое современное локальное межэтническое сообщество занимает некое социокультурное пространство (например, пространство крупного города) и представляет собой территорию, которая «отражает не столько межпоколенную историю людей, запечатлеваемую в культурном ландшафте, сколько особенности функционального взаимодействия между группами людей» (Лебедева, 2010: 31). Соответственно, этнокультурный неотрадиционализм возникает в процессе воспроизводства традиций в условиях не монолитного, а мозаичного социального пространства. При этом нередко носителями этнических традиций в данном пространстве являются мигранты (в широком смысле слова), которые воспроизводят свою этноспецифичность в отрыве от материнского этноса. И здесь актуализируется важная роль органов власти разного уровня. Национальная политика, ориентированная преимущественно на этнокультурный обмен и обогащение посредством мероприятий этнофестивального характера, оказывается недостаточной для коррекции стереотипов и заблуждений принимающего сообщества в отношении мигрантов, сформированных на основе этнокультурных отличий. Соответственно, важной социальной задачей представляется формирование продуманной национальной политики в отношении мигрантов (Мадюкова, Персидская, 2014). Стоит согласиться с мнением Е. Ф. Фурсовой и И. Ю. Аксеновой о том, «что современные управленческие структуры, образовательные и культурные учреждения оказались не готовы к наблюдаемому сегодня у народов повышенному вниманию к своему происхождению и традиционной культуре, известному в мире как “взрыв этничности”...» (Фурсова, Аксенова, 2013: 292). Деятельности культурных центров, у которых нередко встречается «шаблонный» подход, недостаточно, как недостаточно и мероприятий преимущественно этнофестивального характера. На наш взгляд, органы власти должны быть заинтересованы в предупреждении возникновения анклавных формирований этнокультурных общностей, живущих по альтернативным законам. Справедливо замечание, что «разнообразие культур и верований продуктивно, если оно сопровождается стремлением к диалогу и поиску компромиссов, а не взаимной изоляцией и параллельным непересекающимся сосуществованием» (Солодова, 2010: 78). Соответственно, если потенциал этнокультурного неотрадиционализма использовать в государственной, региональной и муниципальной национальной политике, то государственная поддержка будет содействовать укреплению общенациональной идентичности за счет действия механизма интеркультурного признания, поможет выявить негативные последствия процессов социальнотерриториального исключения, а также может быть использовано органами власти для регулирования этих процессов на основе принятия инокультурных традиций. Важной задачей здесь представляется интеграция деятельности органов власти в области социальной, культурной, экономической и национальной политики. Такая интеграция будет способствовать не только 
гармонизации межэтнических отношений, но и росту экономического и социального благополучия представителей межэтнических сообществ.

\section{СПИСОК ЛИТЕРАТУРЫ}

Александров, В. Б. (1991) Традиция и духовность // Человек и культурно-историческая традиция : сб. науч. трудов / отв. ред. Б. Л. Губман. Тверь : ТвГУ. 118 с. С. $4-12$.

Апажева, С. С. (2003) Традиция в российском социуме : автореф. дис. ... канд. филос. наук. Нальчик. 24 с.

Долженкова, О. В., Попков, Ю. В. (2016) Этническая идентичность в контексте теории потребностей // Знание. Понимание. Умение. № 2. С. 53-65. DOI: $10.17805 /$ zpu.2016.2.5

Ерохина, Е. А., Мадюкова, С. А., Персидская, О. А. (2015) Межэтническое сообщество Республики Алтай: этносоциальные и этнокультурные процессы // Философия образования. № 1 (58). С. 165-177.

Ерохина, Е. А., Мадюкова, С. А. (2017) Современные функции традиционного костюма // Народный костюм в Сибири : сб. тр. конф. Новосибирск : Ин-т археологии и этнографии СО РАН. 300 с. С. 163-168.

Ефименко, М. Н. (2001) Религиозная традиция как предмет социальнофилософского анализа : автореф. дис. ... д-ра филос. наук. М. 36 с.

Зарубина, Н. Н. (1998) Социально-культурные основы хозяйства и предпринимательства. М. : Магистр. 360 с.

Захаров, Н. В., Луков, В. А. (2017) Тезаурусность шекспировских исследований // Знание. Понимание. Умение. № 2. C. 152-170. DOI: 10.17805/ zpu.2017.2.12

Лебедева, С. О. (2010) Город как социокультурное пространство // Известия Волгоградского государственного технического университета. Серия: Проблемы социально-гуманитарного знания. Т. 8. Вып. 9 (69). С. 29-32.

Луков, В. А., Луков, Вл. А. (2006) Теория тезаурусного подхода // Гуманитарное знание: тенденции развития в XXI веке : В честь 70-летия Игоря Михайловича Ильинского / колл. моногр. ; под общ. ред. В. А. Лукова. М. : Изд-во Нац. ин-та бизнеса. 680 с. С. 557-565.

Мадюкова, С. А. (2008) Проблемы воспроизводства этничности с точки зрения концепции социокультурного неотрадиционализма // Гуманитарные науки в Сибири. № 1. С. 65-69.

Мадюкова, С. А., Персидская, О. А. (2014) Региональная специфика национальной политики в Республике Алтай // Вестник Новосибирского государственного университета. Серия: Философия. Т. 12. Вып. 2. С. 150-156.

Мадюкова, С. А., Попков, Ю. В. (2010) Социокультурный неотрадиционализм: воспроизведение традиций и воспроизводство этничности // Регионы России для устойчивого развития: образование и культура народов Российской Федерации : мат. Межд. науч.-практич. конф. Новосибирск : ЗАО ИПП «Офсет». 1143 с. С. 821-833.

Мархинин, В. В., Удалова, И. В. (2014) Межэтническое сообщество как социокультурный концепт (постановка проблемы) // Вестник Новосибирско- 
го государственного университета. Серия: Философия. Т. 12. Вып. 1. С. 70 78.

Пика, А. И. (1996) Неотрадиционализм на российском Севере: идти в будущее, не забывая прошлого // Социологические исследования. № 11. С. 47-53.

Попков, Ю. В. (2013) Региональные особенности этнонациональной политики [Электронный ресурс] // Новые исследования Тувы. № 4. С. 9-28. URL: https://www.tuva.asia/journal/issue_20/6749-popkov.html [архивировано в WaybackMachine] (дата обращения: 10.04.2019).

Попков, Ю. В., Тюгашев, Е. А. (2017) Феномен города как межэтнического сообщества // ЭКО. № 10 (520). С. 7-19.

Солодова, Г. С. (2010) Мигранты-мусульмане - установки и практики в контексте российского общества // Вестник Новосибирского государственного университета. Серия: Философия. Т. 8. Вып. 3. С. 77-83.

Фурсова, Е. Ф., Аксенова, И. Ю. (2013) Традиции и новации в современной праздничной культуре: к постановке проблемы на примере Сибири // Вестник Новосибирского государственного университета. Серия: История, филология. Т. 12. № 3. С. 292-298.

Шергалиева, М. Т. (2014) К методологии проблемы идентичностей: социальная, личная, этническая и гражданская // Система ценностей современного общества. № 33. С. 100-105.

Этнокультурный комплекс «Алдын-Булак» (б/д) [Электронный ресурс] // TOUVA. URL: http://touva-go.ru/product/item/etnokulturnyiy-kompleks-aldyinbulak.html [архивировано в WaybackMachine] (дата обращения: 10.04.2019).

Дата поступления: 11.04.2019 2.

\section{REFERENCES}

Aleksandrov, V. B. (1991) Traditsiia i dukhovnost' [Tradition and spirituality]. In: Chelovek i kul'turno-istoricheskaia traditsiia [Man and culture-historical tradition] : A collection of research papers / ed. by B. L. Gubman. Tver : Tver State University Publ. 118 p. Pp. 4-12. (In Russ.).

Apazheva, S. S. (2003) Traditsiia v rossiiskom sotsiume [Tradition in Russiam society] : Abstract of the diss. ... Candidate of Philosophy. Nalchik. 24 p. (In Russ.).

Dolzhenkova, O. V. and Popkov, Yu. V. (2016) Etnicheskaia identichnost' v kontekste teorii potrebnostei [Ethnic identity in the context of theory of needs]. Znanie. Ponimanie. Umenie, no. 2, pp. 53-65. (In Russ.). DOI: 10.17805/ zpu.2016.2.5

Erokhina, E. A., Madyukova, S. A. and Persidskaia, O. A. (2015) Mezhetnicheskoe soobshchestvo Respubliki Altai: etnosotsial'nye i etnokul'turnye protsessy [Interethnic community of the Altai Republic: Ethnosocial and ethnocultural processes]. Filosofiia obrazovaniia, no. 1 (58), pp. 165-177. (In Russ.).

Erokhina, E. A. and Madyukova, S. A. (2017) Sovremennye funktsii traditsionnogo kostiuma [Contemporary functions of traditional costume]. In: Narodnyi kostium v Sibiri [Folk costume in Siberia] : Proceedings. Novosibirsk : 
Publ. of the Institute of Archaeology and Ethnography, Siberian Branch, RAS. 300 p. Pp. 163-168. (In Russ.).

Efimenko, M. N. (2001) Religioznaia traditsiia kak predmet sotsial'nofilosofskogo analiza [Religious tradition as a subject of socio-philosophical analysis] : Abstract of the diss. ... Doctor of Philosophy. Moscow. 36 p. (In Russ.).

Zarubina, N. N. (1998) Sotsial'no-kul'turnye osnovy khoziaistva i predprinimatel'stva [Socio-cultural foundations of economy and entrepreneurship]. Moscow : Magistr Publ. 360 p. (In Russ.).

Zakharov, N. V. and Lukov, V. A. (2017) Tezaurusnost' shekspirovskikh issledovanii [Thesaurus foundation of Shakespearean studies]. Znanie. Ponimanie. Umenie, no. 2, pp. 152-170. (In Russ.). DOI: 10.17805/zpu.2017.2.12

Lebedeva, S. O. (2010) Gorod kak sotsiokul'turnoe prostranstvo [The city as sociocultural space]. Izvestiia Volgogradskogo gosudarstvennogo tekhnicheskogo universiteta. Seriia: Problemy sotsial'no-gumanitarnogo znaniia, vol. 8, issue 9 (69), pp. 29-32. (In Russ.).

Lukov, V. A. and Lukov, Vl. A. (2006) Teoriia tezaurusnogo podkhoda [Theory of the thesaurus approach]. In: Gumanitarnoe znanie : tendentsii razvitiia $v$ XXI veke [Humanities knowledge: Prospects of development in the 21st century] : In honour of the 70th anniversary of Igor Mikhailovich Ilinskiy] / ed. by. V. A. Lukov. Moscow : National Institute of Business Publ. 680 p. Pp. 557-565. (In Russ.).

Madyukova, S. A. (2008) Problemy vosproizvodstva etnichnosti s tochki zreniia kontseptsii sotsiokul'turnogo neotraditsionalizma [Problems of ethnicity reproduction from the point of view of the conception of socio-cultural neotraditionalism]. Gumanitarnye nauki v Sibiri, no. 1, pp. 65-69. (In Russ.).

Madyukova, S. A. and Persidskaia, O. A. (2014) Regional'naia spetsifika natsional'noi politiki $\mathrm{v}$ Respublike Altai [Regional specifics of the nationalities policy in the Altai Republic]. Vestnik Novosibirskogo gosudarstvennogo universiteta. Seriia: Filosofiia, vol. 12, issue 2, pp. 150-156. (In Russ.).

Madyukova, S. A. and Popkov, Yu. V. (2010) Sotsiokul'turnyi neotraditsionalizm: vosproizvedenie traditsii i vosproizvodstvo etnichnosti [Sociocultural neotraditionalism: Rehabilitation of traditions and reproduction of ethnicity]. In: Regiony Rossii dlia ustoichivogo razvitiia: obrazovanie i kul'tura narodov Rossiiskoi Federatsii [Regions of Russia for sustainable development: Education and Culture of the Peoples of the Russian Federation] : Proceedings of the International research-to-practice conference. Novosibirsk : Ofset Printing Plant. 1143 p. Pp. 821-833. (In Russ.).

Markhinin, V. V. and Udalova, I. V. (2014) Mezhetnicheskoe soobshchestvo kak sotsiokul'turnyi kontsept (postanovka problemy) [Interethnic community as a sociocultural concept (Problem statement)]. Vestnik Novosibirskogo gosudarstvennogo universiteta. Seriia: Filosofiia, vol. 12, issue 1, pp. 70-78. (In Russ.).

Pika, A. I. (1996) Neotraditsionalizm na rossiiskom Severe: idti v budushchee, ne zabyvaia proshlogo [Neotraditionalism in the Russian north: Move into 
the future without forgetting the past]. Sotsiologicheskie issledovaniia, no. 11, pp. 47-53. (In Russ.).

Popkov, Yu. V. (2013) Regional'nye osobennosti etnonatsional'noi politiki [Regional features of ethnonational policy]. Novye issledovaniia Tuvy, no. 4, pp. 9-28. [online] Available at: https://www.tuva.asia/journal/issue 20/6749-popkov.html [archived in WaybackMachine] (accessed 10.04.2019). (In Russ.).

Popkov, Yu. V. and Tiugashev, E. A. (2017) Fenomen goroda kak mezhetnicheskogo soobshchestva [Phenomenon of the city as an interethnic community]. $E K O$, no. 10 (520), pp. 7-19. (In Russ.).

Solodova, G. S. (2010) Migranty-musul'mane - ustanovki i praktiki v kontekste rossiiskogo obshchestva [Migrant Muslims: Attitudes and practices in the context of Russian society]. Vestnik Novosibirskogo gosudarstvennogo universiteta. Seriia: Filosofiia, vol. 8, issue 3, pp. 77-83. (In Russ.).

Fursova, E. F. and Aksenova, I. Yu. (2013) Traditsii i novatsii v sovremennoi prazdnichnoi kul'ture: k postanovke problemy na primere Sibiri [Traditions and innovations in contemporary festive culture: Problem definition in the case of Siberia]. Vestnik Novosibirskogo gosudarstvennogo universiteta. Seriia: Istoriia, filologiia, vol. 12, no. 3, pp. 292-298. (In Russ.).

Shergalieva, M. T. (2014) K metodologii problemy identichnostei: sotsial'naia, lichnaia, etnicheskaia i grazhdanskaia [Towards the methodology of the problem of identities: Social, personal, ethnic and civil]. Sistema tsennostei sovremennogo obshchestva, no. 33, pp. 100-105. (In Russ.).

Etnokul'turnyi kompleks «Aldyn-Bulak» [Ethnocultural complex "AldynBulak"]. (s/d) TOUVA [online] Available at: http://touva-go.ru/product/item/ etnokulturnyiy-kompleks-aldyin-bulak.html [archived in WaybackMachine] (accessed 10.04.2019). (In Russ.).

Submission date: 11.04.2019.

Мадюкова Светлана Александровна - кандидат философских наук, старший научный сотрудник Института философии и права Сибирского отделения Российской академии наук. Адрес: 630090, г. Новосибирск, ул. Николаева, 8. Тел: +7 (383) 330-22-40. Эл. адрес: sveiv7@mail.ru

Madyukova Svetlana Aleksandrovna, Candidate of Philosophy, Senior Researcher, Institute of Philosophy and Law, Siberian Branch, Russian Academy of Sciences. Postal address: 8, Nikolaeva St., 630090 Novosibirsk, Russian Federation. Tel: +7 (383) 330-09-75. E-mail: sveiv7@mail.ru

\section{Для ичитирования:}

Мадюкова С. А. Потенциал этнокультурного неотрадиционализма в социальном регулировании межэтнических отношений [Электронный ресурс] // Горизонты гуманитарного знания. 2019. № 2. C. 61-71. URL: http://journals. mosgu.ru/ggz/article/view/1004 (дата обращения: дд.мм.гггг). DOI: 10.17805/ ggz.2019.2.4 